\title{
Polling the readers of Skeletal Radiology
}

\author{
Juerg Hodler • Mark J. Kransdorf • Daniel I. Rosenthal
}

Published online: 30 July 2014

(C) ISS 2014

A wise old physician once told me that he would never agree to do a book review because reviewing someone's book is a bit like reviewing their spouse. There is no "constructive criticism" that is welcome.

For a scholarly publication such as Skeletal Radiology, letters to the Editor can pose a similar risk. As pointed out by Wikipedia (http://en.wikipedia.org/wiki/Letter_to_the_ editor), "In academic publishing, letters to the editor of an academic journal are usually open postpublication reviews of a paper, often critical of some aspect of the original paper. "Such letters are likely to be critical of the author, the reviewers who accepted the paper, and, by implication, the editors who selected it. Letters are not subject to the same standards of evidence and peer review as a scientific publication; they can therefore be seen as a "cheap shot" taken at someone's hard work.

Despite growth in recent years, the world of musculoskeletal diagnosis is a small one; it is highly likely that the authors of a letter and the authors of the paper it addresses will be known to each other.

For these reasons, Skeletal Radiology has, with very rare exceptions, declined the publication of letters to the editor.

And yet, letters can also add a certain amount of liveliness to a publication. The letter writer might have arcane knowledge to share, and the author gets the satisfaction of knowing that someone somewhere has read and thought about what he or she has written.

Should we change our policy and accept letters? The Editors request your feedback on this issue.

(1) Should we accept letters at all?

(2) Should we accept letters on subjects that do not directly relate to an article published in Skeletal Radiology?

a. For example, letters dealing with educational, economic, or political issues that relate to the world of musculoskeletal diagnosis or treatment?

(3) If we do accept letters, what limitations are appropriate?

We would value feedback from the readers of Skeletal Radiology. If you have an opinion that you would like to bring to the attention of the Editors, please send an email to DIROsenthal@partners.org. Our plan is to discuss the subject at the next meeting of the Editorial Board (October 2014) and reach a decision shortly afterward.

Juerg Hodler, MD

Mark Kransdorf, MD

Daniel Rosenthal, MD

J. Hodler

University Hospital Zurich, AUFN C 18, Raemistrasse 100,

8091 Zurich, Switzerland

e-mail: juerg.hodler@usz.ch

\section{J. Kransdorf}

Mayo Clinic, Phoenix, AZ, USA

e-mail: kransdorf.mark@mayo.edu

D. I. Rosenthal $(\bowtie)$

Massachusetts General Hospital, Boston, MA, USA

e-mail: DIRosenthal@partners.org 